\title{
Longitudinal variation in muscle protein expression and contraction kinetics of largemouth bass axial muscle
}

\author{
Tierney M. Thys ${ }^{1, *}$, Jason M. Blank ${ }^{2,3}$, David J. Coughlin ${ }^{4, *}$ and Fred Schachat ${ }^{2}$ \\ ${ }^{1}$ Department of Zoology, Duke University, Durham, NC 27708, USA; ${ }^{2}$ Department of Cell Biology, Duke University, \\ Durham, NC 27710, USA; ${ }^{3}$ Hopkins Marine Station, Stanford University, Oceanview Boulevard, Pacific Grove, \\ CA 93950, USA; ${ }^{4}$ Department of Biology, Widener University, Chester, PA 19013, USA \\ *Present address: Sea Studios Foundation, 810 Cannery Row, Monterey, CA 93940, USA \\ $¥$ Author for correspondence (coughlin@pop1.science.widener.edu)
}

Accepted 24 September 2001

\begin{abstract}
Summary
The present study investigates muscle protein expression in largemouth bass Micropterus salmoides through intra- and intermyomeric comparisons of white muscle. Using denaturing SDS-polyacrylamide gel electrophoresis, muscle protein expression in the arm and cone regions of sequential myomeres was compared for three bass. Low percentage $(4.75 \%)$ polyacrylamide-SDS gels and cyanogen bromide ( $\mathrm{CNBr}$ ) peptide mapping revealed no obvious intramyomeric differences between the myosin heavy chains of the arm and cone regions. Electrophoresis of myofibrils and muscle homogenates on higher percentage gels also failed to demonstrate any

caudal muscle had a lower total parvalbumin content than rostral muscle. Since troponin $T$ and parvalbumin have been implicated in the regulation of skeletal muscle kinetics, longitudinal variation in muscle contraction kinetics was predicted. Subsequent experiments revealed that bass rostral white muscle showed faster rates of activation and relaxation than more caudal muscle, as has been observed in white muscle of other fish species. Rostral-caudal variations in white muscle protein composition and contractile properties are predicted to affect patterns of power production during fast, unsteady swimming.
\end{abstract} significant differences between arm and cone regions in either the myosin light chains or any of the major insoluble and soluble contractile proteins. Two differences were discovered intermyomerically: (i) the ratio of two troponin $T$ isoforms changed from head to tail and (ii)

Key words: largemouth bass, Micropterus salmoides, gel electrophoresis, myosin, troponin T, parvalbumin, white muscle, fish, contraction kinetics, activation, relaxation.

\section{Introduction}

The function of the myotomal muscles in swimming fishes has received considerable scrutiny over the last decade. Much of this work has focused on steady swimming behaviour and the lateral red or aerobic muscle, due in part to its simple architecture and accessibility for physiological measurements. This research has shown significant variation in longitudinal (rostral-caudal) patterns of red muscle activation conditions in vivo and red muscle contractile properties and power production in vitro (Rome et al., 1993; Wardle et al., 1995; Altringham and Ellerby, 1999; Coughlin, 2000; McGlinchey et al., 2001). However, comparatively little empirical analysis has been carried out on the patterns of power production of the white or anaerobic muscle during unsteady swimming behaviours such as burst and coast swimming and fast starts, perhaps due to the complex architecture of the white muscle of most fishes. Yet, in many fishes, acquisition of food and escape from predators depend on white muscle activity. Efforts to examine white muscle function during swimming must begin with an understanding of the structure and physiological capabilities of that muscle.

This paper focuses on the protein composition and contractile properties of axial white muscle of largemouth bass Micropterus salmoides (Lacépède). Bass were selected for this study for two reasons. First, the detailed electromyographic studies provide a background on the functional role of the white muscle in these fishes (Jayne and Lauder, 1994, 1995a; Thys, 1997). Second, largemouth bass (Order Perciformes) are phylogenetically distinct from Atlantic cod Gadus morhua (Order Gadiformes), the subject of previous studies on contractile properties and muscle protein composition (Davies et al., 1995; Thys et al., 1998). The major teleostean orders began diverging in the Jurassic Period, over 150 million years ago (Long, 1995), offering ample evolutionary time for suites of potentially diverse axial muscle properties to arise independently. The white muscle of bass and most fishes is organized in a W shape, with long, anterior-pointing epaxial and hypaxial arms found above and below an anterior-pointing cone composed of both epaxial and hypaxial regions. The arm and cone regions of bass myomeres 
are both morphologically and physiologically distinct (Jayne and Lauder, 1994, 1995a; Thys, 1997). Morphologically, the arm and cone regions can be easily distinguished (the bends of the W are readily apparent). Physiologically, arm and cone regions of a given myomere are activated independently. For instance, as measured via electromyography, the onset time and the duration of muscle activity (i.e. EMG bursts) differ between the arm and the cone regions during high speed, unsteady swimming of bass (Jayne and Lauder, 1995a). Also, arm regions are more commonly and more intensely recruited compared to cone regions during prey strikes in bass (Thys, 1997). These studies suggest that arm and cone regions have different patterns of innervation.

Similar to the fish myomere, single muscles with morphologically and neurologically distinct regions can be found in many vertebrates, e.g. pigeon pectoralis (Shigeoka, 1997) and feline sartorius (Hoffer et al., 1987) muscles. In both birds and mammals, different regions of the same muscle can express differing suites of contractile proteins, e.g. varying myosin heavy chains are found in chicken posterior latissimus dorsi (Rushbrooke et al., 1988) and rabbit extraocular muscle (Briggs et al., 1988). With this in mind, the following study explores intramyomeric variation in muscle protein composition, comparing the arm and cone regions of bass white muscle myomeres at several longitudinal positions.

Since most fish display rostral-caudal variations in contractile properties of the axial muscle (Altringham and Ellerby, 1999), the same protein analyses were carried out for intermyomeric or longitudinal patterns of white muscle protein expression. Having observed rostral-caudal differences in protein composition, isometric contraction kinetics were examined to determine the physiological effects of variation in muscle proteins.

\section{Materials and methods \\ Experimental animals}

For protein analysis, three largemouth bass (standard length $\mathrm{SL}=242 \pm 20 \mathrm{~mm}$, mean \pm S.D.), were caught in local ponds of Durham and Chapel Hill, North Carolina, USA, between the months of June and August, 1997. All muscle samples were dissected immediately from freshly dead or from bass fresh frozen and stored at $-20^{\circ} \mathrm{C}$ for less than 1 week.

For muscle mechanics experiments, ten largemouth bass ( $\mathrm{SL}=139 \pm 7 \mathrm{~mm}$, mean \pm S.D.) were acquired from a commercial fish hatchery in Chester County, Pennsylvania, USA in May 1998. The fish were maintained for up to 1 month on a diet of live fish in a recirculating aquarium system at $20^{\circ} \mathrm{C}$.

\section{Myofibril preparation}

After removal of the skin, superficial white muscle samples, approximately $0.5-1.0 \mathrm{~g}$, were dissected from the epaxial arm and cone regions of sequential myomeres. Epaxial muscle was chosen for two reasons: (1) previous physiological work focused on the epaxial muscle (Thys, 1997); and (2) hypaxial muscle has the added complication of housing the coelom and, therefore, the shape of the arm region varies substantially from anterior to posterior. Left-side axial muscle was sampled in all bass, MS01-MS03, and the right side was also sampled in bass MS03. All muscle samples were either frozen in liquid nitrogen and pulverized or frozen at $-80^{\circ} \mathrm{C}$ and minced finely on a chilled glass plate to break up the connective tissue thoroughly. Minced samples were suspended in approximately three volumes of buffer A $\left(15 \mathrm{mmol}^{-1}\right.$ Tris, $\mathrm{pH} 7.6,100 \mathrm{mmoll}^{-1} \mathrm{NaCl}, 4 \mathrm{mmoll}^{-1}$ EGTA, $2 \mathrm{mmoll}^{-1}$ $\mathrm{MgCl}_{2}, \quad 7 \mathrm{mmoll}^{-1} \quad \beta$-mercaptoethanol, $\quad 0.1 \mathrm{mmoll}^{-1}$ phenylmethylsulphonylfluoride (PMSF), and $75 \mu \mathrm{g} \mathrm{ml}^{-1}$ each of antipain, leupeptin and pepstatin A). Samples were vortexed, centrifuged at $16,000 \mathrm{~g}$ for $12 \mathrm{~s}$, and $1 \mathrm{ml}$ of buffer B (same as buffer A, but with only $0.3 \mu \mathrm{g} \mathrm{ml}^{-1}$ leupeptin, antipain and pepstatin) was added to the remaining pellets. The samples were vortexed, centrifuged and the remaining pellets incubated in $1 \mathrm{ml}$ of buffer $\mathrm{C}$ (same as buffer B, but plus $2 \%$ Triton X100) for $10 \mathrm{~min}$. Pellets were washed twice more in buffer B and resuspended in one volume of buffer B before they were made into gel samples.

\section{$S D S-P A G E$}

\section{Sample preparation}

Gel samples were prepared in by diluting myofibrils $1: 1$ with $2 \times$ Laemmli reducing buffer $\left(2 \%\right.$ SDS, $50 \mathrm{mmol}^{-1}$ Tris, pH 6.8, $20 \%$ glycerol, $0.1 \% \beta$-mercaptoethanol, $0.5 \%$ Bromophenol Blue). Samples were then heated for $3 \mathrm{~min}$ at $100^{\circ} \mathrm{C}$, frozen until solid, reheated for $2 \mathrm{~min}$ at $100^{\circ} \mathrm{C}$ and centrifuged to pellet debris.

\section{Gel set-up}

SDS-PAGE was performed according to a procedure modified from Laemmli (1970). $4.75 \%, 10.5 \%$ and $12.5 \%$ polyacrylamide-SDS gels were used and all gel solutions were polymerized by the addition of ammonium persulfate (APS) and $N, N, N^{\prime}, N^{\prime}$-tetramethylethylenediamine (TEMED). Gels $\left(13.5 \mathrm{~cm} \times 14.1 \mathrm{~cm} ; 0.75 \mathrm{~mm}\right.$ thick) were run at $8^{\circ} \mathrm{C}$ on Hoefer Scientific Instruments SE500 apparatus. The $4.75 \%$ SDS gel was run at $120 \mathrm{~V}$ at $15^{\circ} \mathrm{C}$ for $80 \mathrm{~min}$. All gels were fixed in $15 \%$ acetic acid for $30 \mathrm{~min}$, rinsed in deionized water and stained overnight with Coomassie Brilliant Blue G250 (363 $\mathrm{mmol} \mathrm{l}^{-1} \quad \mathrm{NH}_{4} \mathrm{SO}_{4}, \quad 140 \mathrm{mmol}^{-1} \quad \mathrm{H}_{3} \mathrm{PO}_{4}, 0.94 \mathrm{moll}^{-1}$ G250 and $20 \%$ methanol) as described (Schachat et al., 1980).

Gels were scanned alongside a calibrated Kodak density step tablet (Cat. no. 1523406), which was used to calibrate the density profiles of each protein band in NIH Image v. 1.61. Stepwise dilutions of muscle protein samples were electrophoresed on separate gels in order to ensure linearity of staining by Coomassie Brilliant Blue G250. Gels were quantified densitometrically and intensity peak plots were exported into the curve-fitting program Jandel PeakFit v. 4, which computes the area under each peak. These values were then imported into Cricket Graph III to construct the figures. 


\section{Troponin purification \\ Myofibril preparation}

Myofibrillar samples were prepared as described above from two fresh white muscle samples $(1.1 \mathrm{~g}$ each) dissected from rostral and caudal arm sites from bass MS02. Pelleted myofibrils were centrifuged, resuspended and incubated on ice for $15 \mathrm{~min}$ in a high-salt solution $\left(1 \mathrm{moll}^{-1} \mathrm{NaCl}\right.$, $2 \mathrm{mmoll}^{-1}$ ATP, $7 \mathrm{mmol}^{-1} \beta$-mercaptoethanol, $0.1 \mathrm{mmoll}^{-1}$ PMSF) in order to dissociate actin from myosin. Following the incubation, the samples were centrifuged for $90 \mathrm{~min}$ at $80,000 \mathrm{~g}$ and the resulting supernatants were dialyzed overnight in a low-salt solution $\left(25 \mathrm{mmol}^{-1} \mathrm{NaCl}\right.$, $15 \mathrm{mmol}^{-1}$ Tris, pH 7.5, $3 \mathrm{mmoll}^{-1} \mathrm{MgCl}_{2}$, $1 \mathrm{mmol}^{-1}$ EGTA) with a change of dialysis solution after the first $4 \mathrm{~h}$. Following dialysis, the samples were centrifuged for $10 \mathrm{~min}$ at $800 \mathrm{~g}$. The resulting supernatants were dialyzed for several hours against hydroxyapatite column buffer $\left(4 \mathrm{mmol} \mathrm{l}^{-1} \mathrm{Na}_{2} \mathrm{HPO}_{4}\right.$, $1 \mathrm{mmol}^{-1} \mathrm{NaH}_{2} \mathrm{PO}_{4}, 0.1 \mathrm{mmol}^{-1} \mathrm{PMSF}, 7 \mathrm{mmoll}^{-1}$ $\beta$-mercaptoethanol, $1 \mathrm{moll}^{-1} \mathrm{NaCl}$ ), after which the samples were loaded onto the hydroxyapatite column.

\section{Hydroxyapatite column chromatography and protein identification}

Hydroxyapatite column chromatography was performed to separate myofibrillar proteins using a protocol modified from that of Eisenberg and Kielley (1974). The column was equilibrated with $5 \mathrm{mmoll}^{-1}$ sodium phosphate buffer $\left(4 \mathrm{mmoll}^{-1} \mathrm{Na}_{2} \mathrm{HPO}_{4}\right.$, $1 \mathrm{mmol} \mathrm{l}^{-1} \quad \mathrm{NaH}_{2} \mathrm{PO}_{4}, \quad 1 \mathrm{moll}^{-1} \mathrm{NaCl}, 4 \mathrm{mmoll}^{-1}$ $\mathrm{MgCl}_{2}, 7 \mathrm{mmoll}^{-1} \beta$-mercaptoethanol, $0.1 \mathrm{mmol} \mathrm{l}^{-1}$ PMSF), and eluted with a linear sodium phosphate gradient [5 $\mathrm{mmoll}^{-1}$ to $300 \mathrm{mmol}^{-1}$ (4:1 ratio of $\mathrm{Na}_{2} \mathrm{HPO}_{4}$ to $\left.\left.\mathrm{NaH}_{2} \mathrm{PO}_{4}\right)\right]$ at a flow rate of $20 \mathrm{ml} \mathrm{h}^{-1}$. Fractions containing protein were analyzed using $12.5 \%$ SDS minigels.

Column fractions containing myosin were used for cyanogen bromide $(\mathrm{CNBr})$ peptide mapping of myosin heavy chains. Additional myofibrillar samples, extracted in a $40 \mathrm{mmol} \mathrm{l}^{-1}$ pyrophosphate solution that preferentially solubilizes myosin, were used to identify fast myosin light chains.

Troponin eluted from the hydroyapatite column as a trimeric complex that was shown in independent studies to be thin filament associated with myofibrils, from which the thick filaments were extracted with pyrophosphate (see above). The identity of the troponin $\mathrm{C}(\mathrm{TnC})$ subunit was confirmed by $\mathrm{Ca}^{2+}$-dependent mobility shifts on SDS-PAGE, troponin I (TnI) was identified as the subunit with which TnC complexed during the mobility shift studies, and the identification of troponin $\mathrm{T}$ was based on its purification as the third member of the trimeric complex eluted from hydroyapatite.

\section{CNBr peptide mapping}

Myosin heavy chains were compared using a $\mathrm{CNBr}$ peptide mapping technique modified from that of Pepinski (1983). $\mathrm{CNBr}$ cleaves myosin at the methionine residues and allows comparison of proteolytic fragments.

Column samples containing myosin were resuspended in $2 \times$ sample buffer $\left(1.25 \mathrm{moll}^{-1}\right.$ Tris, $\mathrm{pH} 6.7,20 \%$ glycerol, $4 \%$ SDS, $14 \mathrm{mmol}^{-1} \beta$-mercaptoethanol $\mathrm{r}$ and Bromophenol Blue) and electrophoresed on a $10.5 \%$ SDS-gel. The gel was stained briefly with Coomassie R250 to visualize the proteins. Bands containing myosin were excised from the gel, washed several

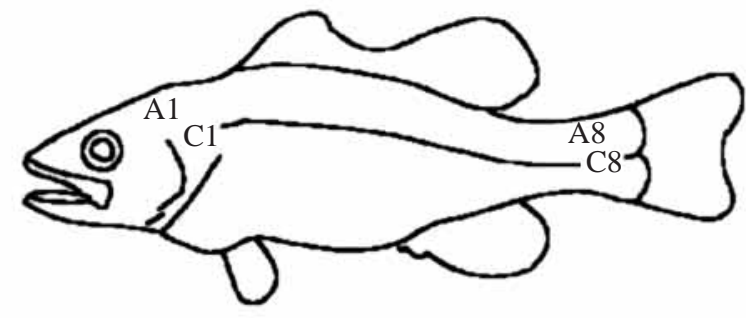

A

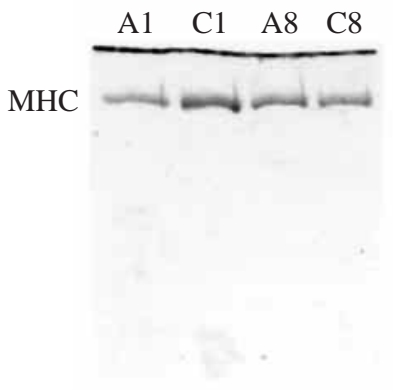

B $\quad$ CnBr peptide map

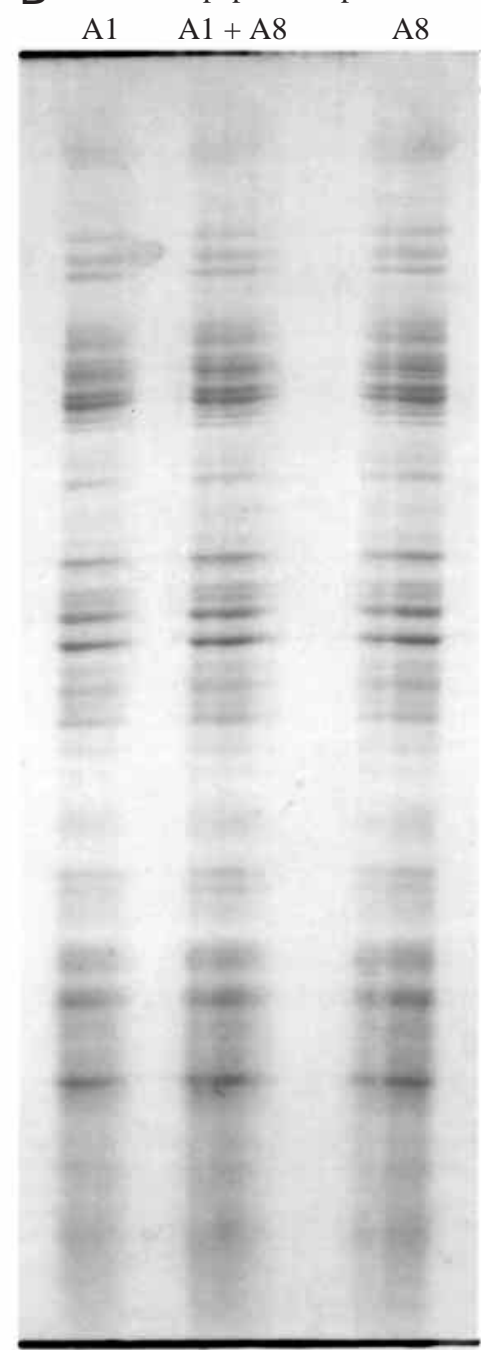

Fig. 1. Comparison of rostral and caudal arm (A1, A8) and cone $(\mathrm{C} 1$, C8) myosin heavy chains (MHC; top). (A) Low percentage $(4.75 \%)$ polyacrylamide-SDS gel. There are no readily apparent significant differences between MHC from either the arm and cone sites or the rostral and caudal sites. (B) Cyanogen bromide (CNBr) peptide map comparing proteolytic fragments of rostral arm, cone and mixed samples. There are no readily apparent differences between them. 


\section{T. M. Thys and others}

times in $\mathrm{H}_{2} \mathrm{O}$, incubated for $30 \mathrm{~min}$ at room temperature in $\mathrm{CNBr}$ solution ( $1 \mathrm{ml}$ formic acid, $1 \mathrm{ml} \mathrm{H}_{2} \mathrm{O}, 8 \mu \mathrm{l} \beta$ mercaptoethanol and $100 \mathrm{mg} \mathrm{ml}^{-1} \mathrm{CNBr}$ ) and centrifuged. Supernatants were removed and the gel slices were washed several times in $\mathrm{H}_{2} \mathrm{O}$ and solution $\mathrm{D}\left(0.5 \mathrm{~mol}^{-1}\right.$ Tris, $\left.\mathrm{pH} 6.8\right)$ and then soaked in Adams buffer $\left(100 \mathrm{mmol}^{-1}\right.$ Tris, $\mathrm{pH} 6.7$, $5 \%$ glycerol, $4 \%$ SDS, 5\% $\beta$-mercaptoethanol, $0.05 \%$ Bromophenol Blue) for $5 \mathrm{~min}$ at $37^{\circ} \mathrm{C}$. The proteolytic fragments on these gel slices were electrophoresed on a $12.5 \%$ SDS-polyacrylamide gel by loading the gel slices directly onto the stacker. The resulting gel was stained with Coomassie Brilliant Blue G250 and peptide maps from the rostral and caudal samples were compared visually.

\section{Immunoblotting}

Myofibrillar homogenates were made from fresh epaxial rostral and caudal arm region samples from bass MS02 (224 mm SL). Samples were minced as described above for the myofibril preparation, then suspended in approximately 5 volumes of buffer $\mathrm{A}$ with the addition of $0.6 \mathrm{moll}^{-1} \mathrm{NaI}$ to solubilize the contractile proteins. Following incubation on ice for $10 \mathrm{~min}$, samples were centrifuged at room temperature for $12 \mathrm{~s}$ at $12,500 \mathrm{~g}$. Gel samples were made from the homogenate supernatants. Duplicate lanes of proteins from the two sample sites were electrophoresed on a $15 \%$ SDS-polyacrylamide gel and stained with Coomassie Brilliant Blue G250.

To identify parvalbumin, one set of the gel lanes was transferred onto nitrocellulose using standard western blotting methods modified from that of Towbin et al. (1979). Following the transfer, Monoclonal Anti-parvalbumin Mouse Ascites Fluid PA-235 (Sigma 3171) was applied to the nitrocellulose and developed according to the protocol outlined in the Vectastain ABC kit. Remaining gel lanes were fixed in $15 \%$ acetic acid, stained with Coomassie Brilliant Blue G250 and compared to the developed blot. Parvalbumin levels were quantified densitometrically and normalized to levels of Coomassie Blue-stained actin using NIH Image.

\section{Muscle mechanics}

To measure the kinetic properties of muscle bundles, largemouth bass were killed and strips of live muscle dissected from three longitudinal positions (rostral $=0.40 L$, where $L$ is total length, middle $=0.6 \mathrm{~L}$ and caudal $=0.75 \mathrm{~L}$ ). The bundles were held at $4{ }^{\circ} \mathrm{C}$ in physiological saline (Altringham and Johnston, 1990) during dissection. Live bundles the length of one myomere were tied to a muscle mechanics apparatus using 9-0 silk sutures. The connective tissue at one end was tied to a force transducer (Entran Load Cell), and the other end was

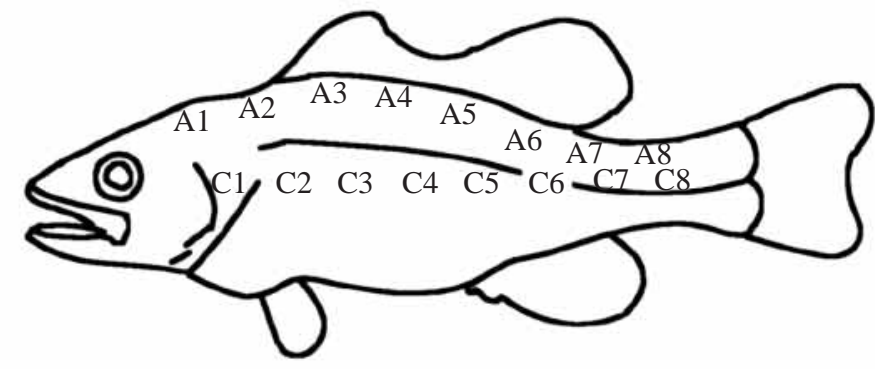

Fig. 2. Comparison of longitudinal contractile protein expression of arm sites (A1-A8) with cone sites (C1-C8) (top). (Bottom) $10.5 \%$ polyacrylamide-SDS gels. Note that the protein distributions revealed on the two gels are not significantly different from one another. Both gels, however, do display a similar longitudinal shift in the ratio of TnT-1 to TnT-2. MHC, myosin heavy chain; MLC, myosin light chain; Tm, tropomyosin; TnI, troponin I; TnC, troponin $\mathrm{C}$; $\mathrm{TnT}$, troponin $\mathrm{T}$.

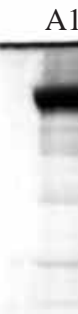

A1 A $2 \mathrm{~A}$ A3 A4 A5 A6 A7 A8

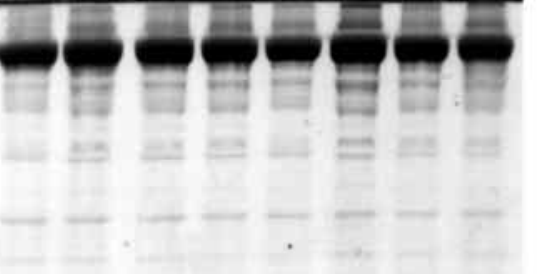
MHC
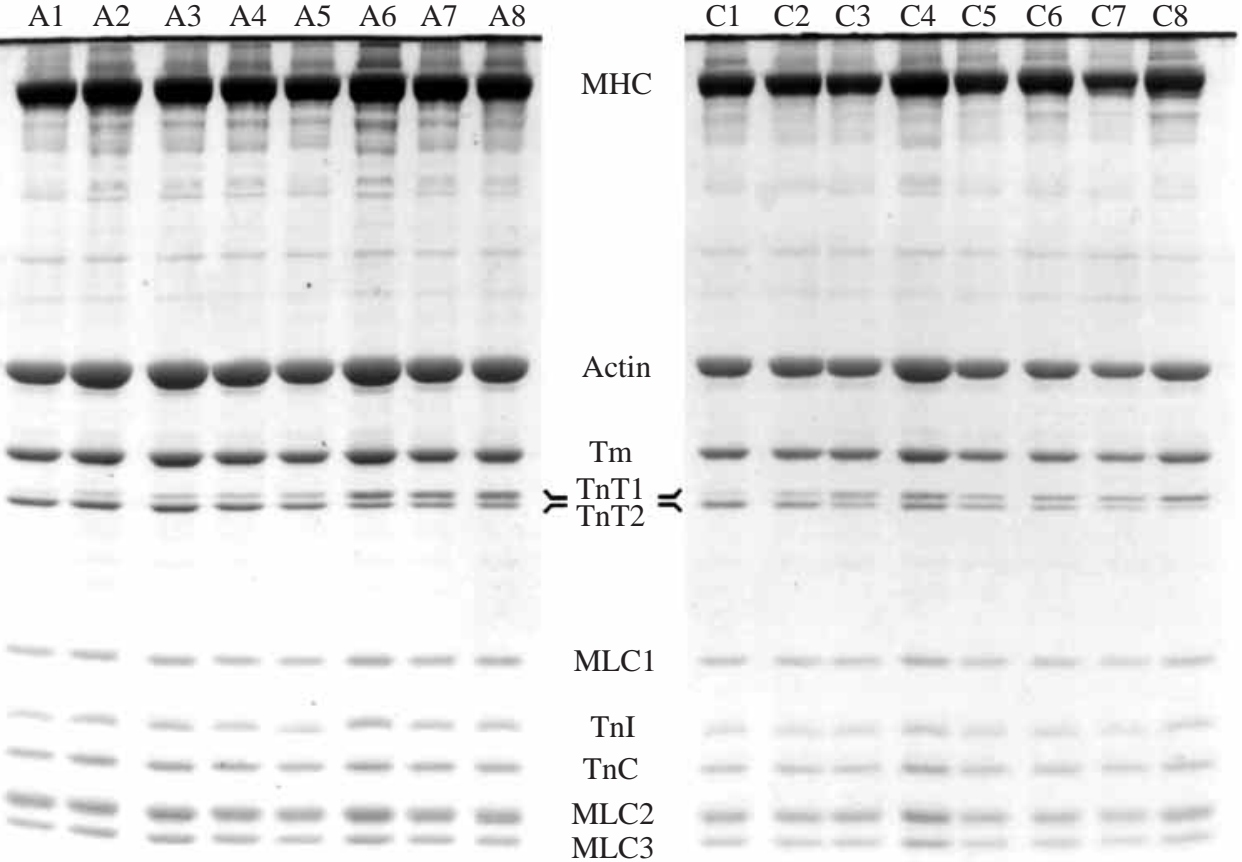

MLC1

TnI

$\mathrm{TnC}$

MLC2

MLC3 
tied to a servomotor system. Isometric contractions were carried out in a bath of physiological saline at $20^{\circ} \mathrm{C}$ with an electrical stimulus supplied via stainless steel electrodes. Tetanic force production was maximized in each muscle bundle by optimizing muscle length and the conditions of the stimulus pulse train (duration, amplitude and frequency of individual pulses and total stimulus duration). Maximal tetanic and twitch contractions were then recorded and analyzed for several kinetic variables: tetanic activation time $t_{\mathrm{A}}$ (time from $10 \%$ to $90 \%$ of total force); tetanic relaxation time $t_{\mathrm{R}}$ (time from 90 to $10 \%$ of total force); twitch time $t_{\mathrm{w}} 90$ (time from stimulation to $90 \%$ recovery); and $t$ w50 (time from stimulation to $50 \%$ recovery, i.e. half peak isometric tension).

To determine the live fibre area, each muscle bundle was stained for $1 \mathrm{~h}$ in Trypan Blue to mark dead tissue, embedded in gelatin and frozen, sections cut at $12 \mu \mathrm{m}$ thick, then stained for mitochondrial content (using succinic dehyrogenase). Live area was then measured from digitized images. A parallel set of experiments were carried out on bass red muscle (Coughlin, 2000), so the differential staining of bass red and white muscle fibres could be determined. All bundles were $100 \%$ white muscle fibres. Dividing bundle force production by the crosssection of live fibres gave the maximum isometric stress in units of $\mathrm{N} \mathrm{m}^{-2}$. The size of muscle bundles did not vary with position. The live muscle cross-sectional area of the bundles was $0.16 \pm 0.08 \mathrm{~mm}^{-2}$ (mean \pm S.D.) and the mean live muscle mass was $5.6 \pm 3.4 \mathrm{mg}$.

\section{Results}

No obvious differences were detected between the myosin heavy chains of the arm and cone regions using the low percentage $4.75 \%$ polyacrylamide-SDS gel and $\mathrm{CNBr}$ peptidemapping techniques (Fig. 1). Separate attempts to separate myosin heavy chains using glycerol-SDS-polyacrylamide gels also failed to resolve any differences in the myosin heavy chain (MHC) composition of cone versus arm regions. While electrophoresis of the bass myofibrils did not reveal any significant arm versus cone differences in any of the major contractile proteins (Fig. 2), a significant difference in thin filament proteins was discovered longitudinally. In both the arm and cone regions, a longitudinal shift occurs in the ratio of two thin filament proteins, identified through column chromatography as two troponin $\mathrm{T}$ (TnT) isoforms (Fig. 3). Rostral muscle samples, A1-A5, are composed primarily of the faster migrating protein, TnT-2 ( $M_{\mathrm{r}}$ 28,120), while caudal muscle samples, A6-A8, have a greater proportion of the slower migrating isoform, TnT-1 ( $M_{\mathrm{r}} 28,800$, Fig. 2). This caudal shift from TnT-2 to TnT-1 occurs in both arm and cone regions of all bass examined (Fig. 4). Comparison of the left and right sides of bass MS03 showed the same pattern for each side of the fish (results not shown).

No rostral-caudal variations in tropomyosin (Tm), troponin $\mathrm{C}(\mathrm{TnC})$ or troponin I (TnI) were observed. For each of these proteins, only a single species was identified, with $M_{\mathrm{r}}$ values of 32,600 for Tm, 18,560 for TnI and 17,900 for TnC (Fig. 2).
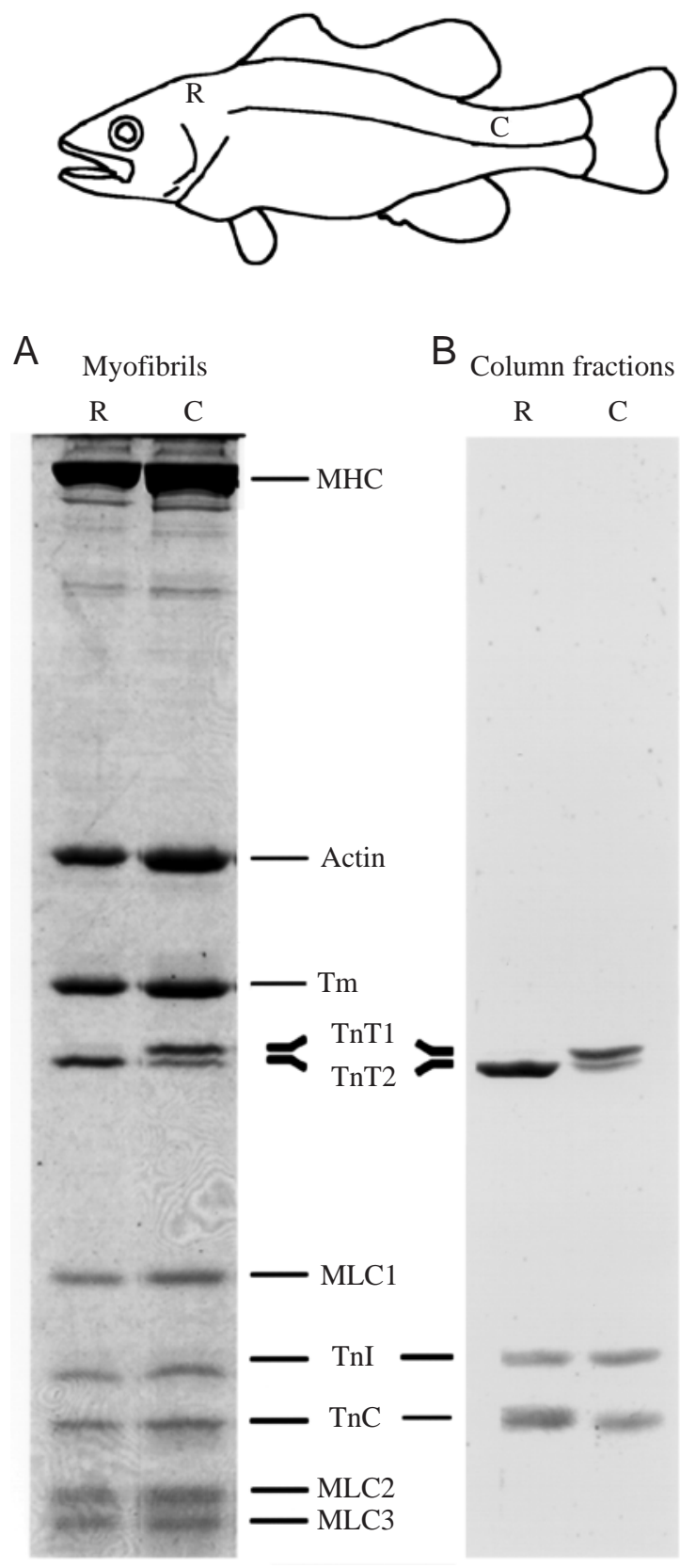

Fig. 3. (A) $10.5 \%$ SDS gel of rostral (R) and caudal (C) bass myofibrils, demonstrating the position of the troponin proteins relative to the myosin light chains. (B) Tropomyosin purification via hydroxyapatite column chromatography. Note that in the rostral column fraction, the faster migrating isoform, TnT-2, predominates while caudally, the slower migrating isoform, TnT-1, predominates. Abbreviations same as in Fig. 2.

Three myosin light chains (MLCs) were identified; MLC-1, MLC-2 and MLC-3 had respective $M_{\mathrm{r}}$ values of 21,300, 17,830 and 17,640 (Fig. 2.) No longitudinal variations were observed in myosin light chains (MLCs).

Electrophoresis of homogenates did reveal an additional rostral-caudal difference in the concentrations of two low molecular mass bands, which were identified as parvalbumins by immunoblotting (Fig. 5). Staining of the slower migrating 


\section{T. M. Thys and others}

parvalbumin, designated parv1, was $21 \%$ more intense in rostral samples than in caudal samples when normalized to actin intensity. The faster migrating parvalbumin, designated parv2, was $25 \%$ more intense rostrally than caudally.

White muscle bundles from each position generated the same amount of force (ANOVA for the effect of longitudinal position on isometric stress, $P=0.871, N=6$ for rostral, $N=5$ for middle and caudal). The isometric stress for all three positions was $134 \pm 15 \mathrm{kN} \mathrm{m}^{-2}$ (mean \pm S.E.M.). The rostral muscle was kinetically faster than caudal muscle (Fig. 6). For all four contraction kinetics variables, there was a significant effect of longitudinal position on time (one-way ANOVAs; $P<0.01$ for all four variables, $t_{\mathrm{A}}, t_{\mathrm{R}}$, $t_{\mathrm{W} 50}$ and $t_{\mathrm{W} 90)}$. For $t_{\mathrm{A}}, t_{\mathrm{R}}$ and $t_{\mathrm{W} 90}$, post hoc multiple comparisons revealed that rostral muscle was significantly faster than both middle and caudal muscle, and that the latter two sites did not differ from each other (Tukey test: rostral versus middle and rostral versus caudal, $P<0.05$; middle versus caudal, $P>0.319)$. For $t \mathrm{w} 50$, rostral muscle was significantly faster than the middle muscle (Tukey test, $P=0.003$ ), but rostral versus caudal positions and middle versus caudal positions did not significantly differ $(P=0.127$ and $P=0.149$, respectively).

\section{Discussion}

With the techniques employed in this study, muscle protein expression does not appear to vary significantly between the arm and cone regions of largemouth bass white muscle. Although there are differences in the functional roles of the arm and cone regions of the myomeres in largemouth bass (Thys, 1997), there are apparently no differences in the protein composition of the white muscle from these two regions of each myomere. The protein composition and function of muscle in fishes commonly does vary along many other trajectories, such as longitudinal position (Thys et al., 1998) (see below) and age (Coughlin et al., 2001). An absence of variation between the arm and cone regions of bass white muscle, despite differences in function, suggests that intramyomeric protein expression may be constrained developmentally. The genetic control of protein expression simply may not allow intramyomeric variation in the muscle composition of arm and cone regions.

Although no major differences were detected intramyomerically, two differences were discovered intermyomerically. Firstly, a longitudinal shift occurs in the proportions of the two isoforms of the thin filament protein troponin T. Secondly, the rostral axial muscle has a higher
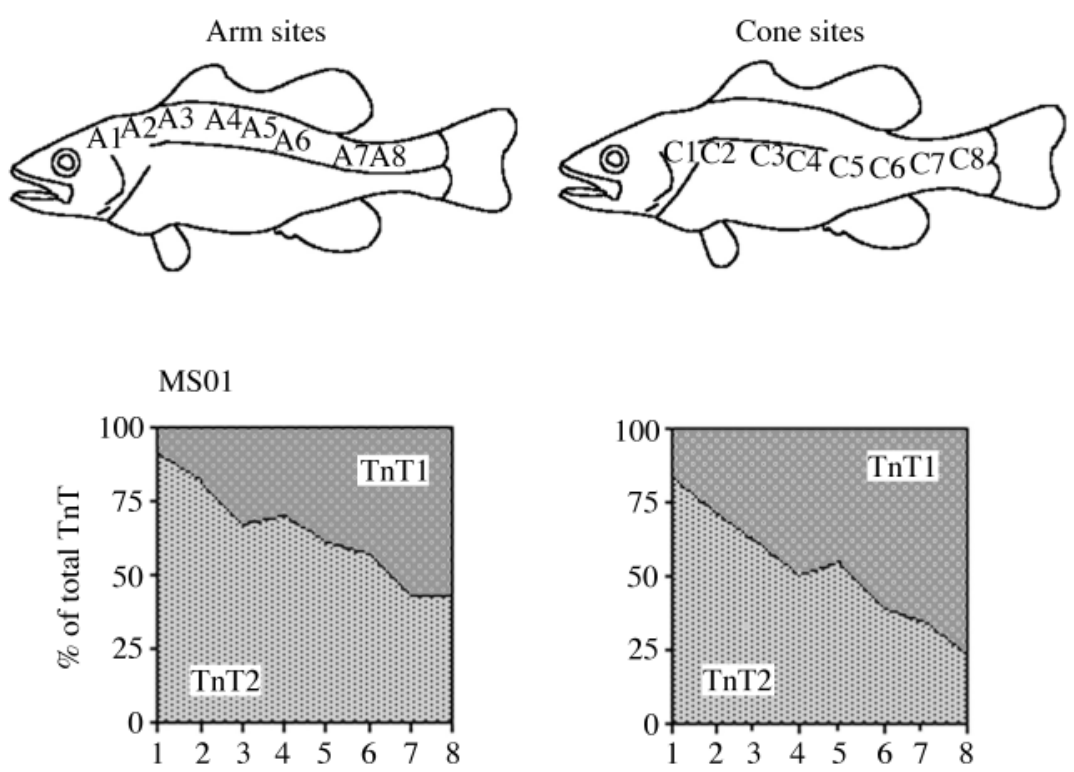

\section{MS02}
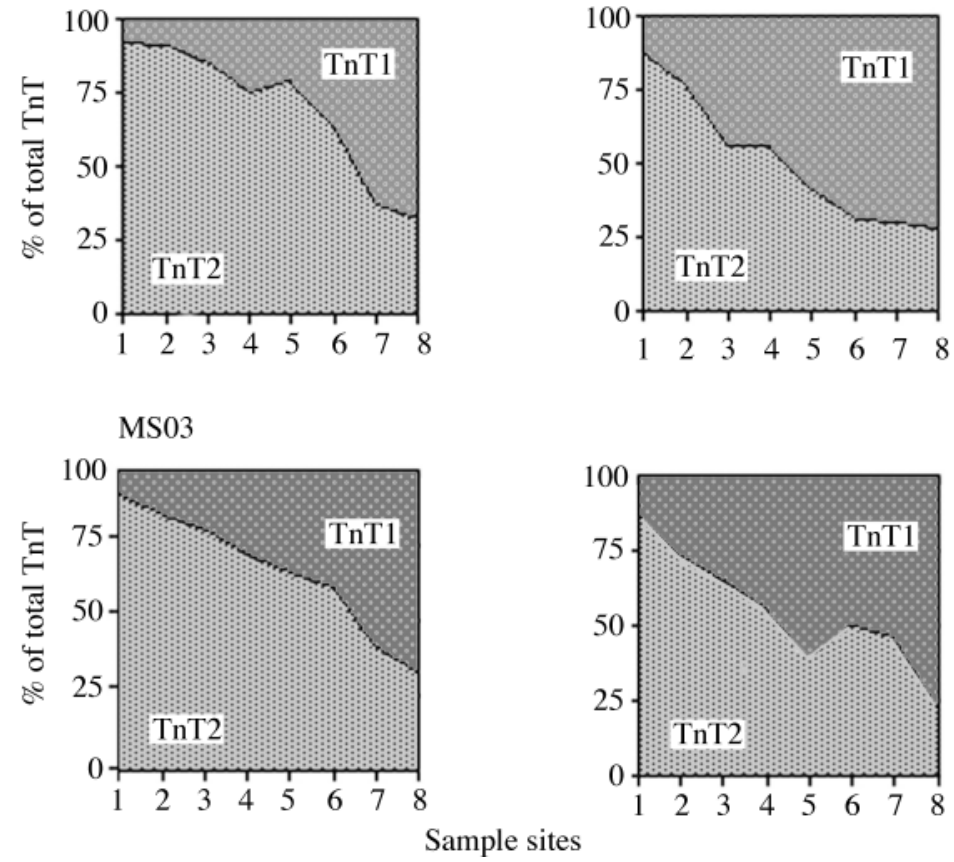

Fig. 4. Measurement of arm and cone TnT-1 to TnT-2 ratios down the left sides of the body for bass MS01 (240 mm SL), MS02 (224 mm SL) and MS03 (264 mm SL). Note that the arm and cone regions display the same trend: rostral samples (A1-A5 and C6-C8) are composed primarily of TnT-2 while caudal samples (A6-A8 and C6-C8) are composed primarily of TnT-1. The postitions of the samples in the fish are shown at the top.

parvalbumin content than the caudal muscle. This longitudinal biochemical heterogeneity in muscle protein expression was correlated with a longitudinal shift in activation and relaxation kinetics. Rostral muscle, which has the fastest rates of activation and relaxation, predominantly expresses the TnT-2 isoform of troponin and has greater parvalbumin content. 


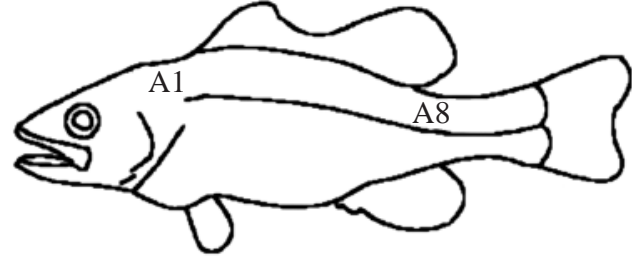

A

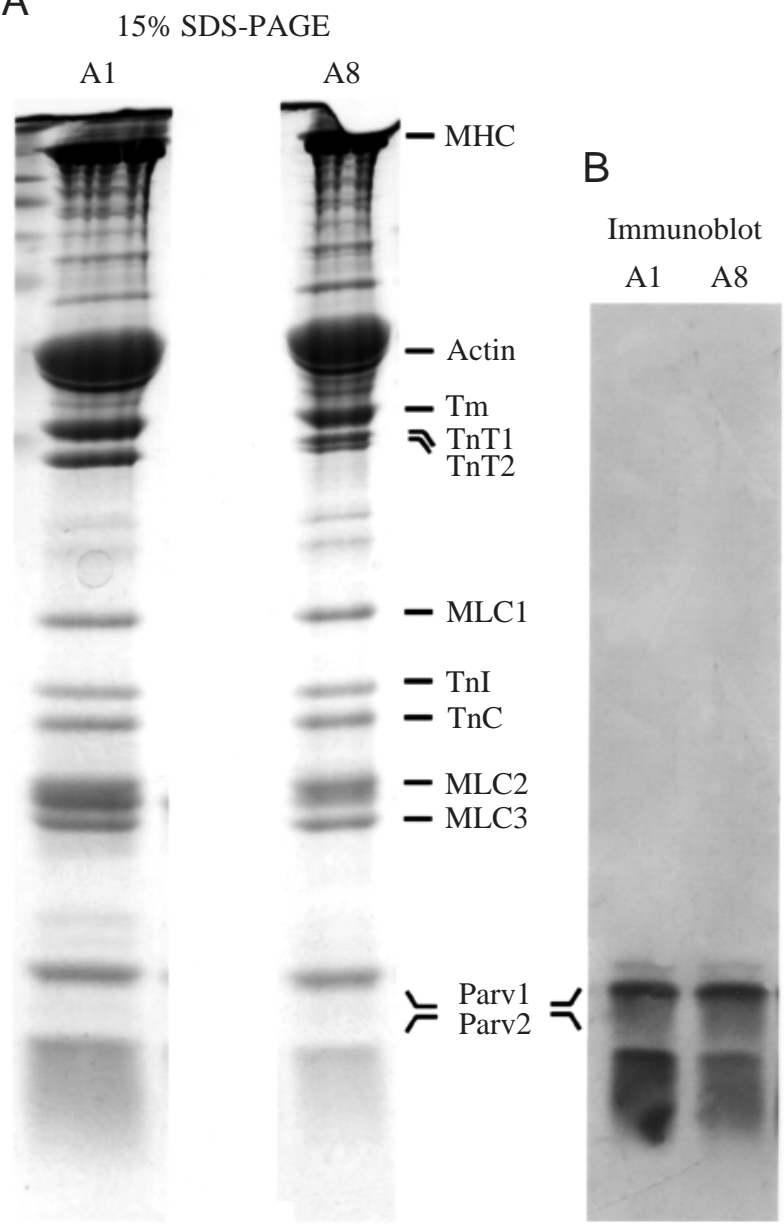

Fig. 5. Immunoblot of rostral and caudal arm myofibrillar homogenates revealing parvalbumin. After electrophoresis on $15 \%$ SDS-polyacrylamide gels (A), bass MS02 (224 mm SL) rostral (A1) and caudal (A8) arm myofibrillar homogenates were transferred to nitrocellulose. Monoclonal anti-parvalbumin mouse ascites fluid PA235 (Sigma 3171) was used to identify parvalbumin in the immunoblot (B). Normalized to actin, the densitometric value of the slower migrating parvalbumin species, parv1, is $21 \%$ greater rostrally than caudally. The faster migrating parvalbumin species, parv 2 , is $25 \%$ greater rostrally than caudally.

Troponin $\mathrm{T}$ has been implicated in affecting activation and relaxation rate in striated muscle (Schachat et al., 1987; Schiaffiano and Reggiani, 1996). Parvalbumin has also been shown to speed up relaxation rate in a dose-dependent manner in mammals (Müntener et al., 1995). The difference in parvalbumin could explain faster rates of relaxation in rostral muscle. Further, since variations in TnT can lead to changes in activation time (Schiaffiano and Reggiani, 1996), the

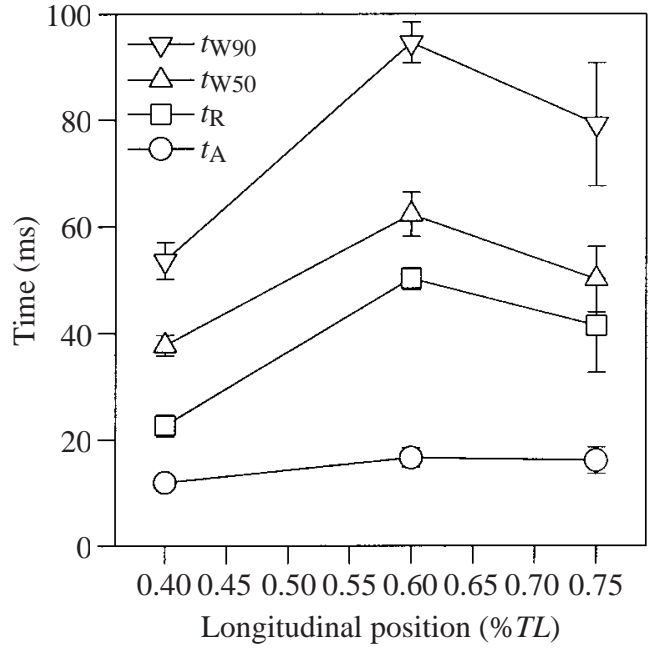

Fig. 6. Contraction kinetics of largemouth bass white muscle. Time of activation $\left(t_{\mathrm{A}}\right)$, time of relaxation $\left(t_{\mathrm{R}}\right)$ and twitch times ( $t_{\mathrm{W} 90}$ and $t_{\mathrm{W} 50}$ ) are plotted against longitudinal position (see text for definitions). For all four variables, there is a significant effect of position on kinetics, with anterior muscle having the fastest time for activation and relaxation (one-way ANOVA, $P<0.01$ for the effect of position on each variable).

correlation between faster activation and greater TnT-2 content suggests that TnT-2 is a kinetically faster form of troponin T than TnT-1.

This suggestion agrees with previous work on Atlantic cod axial muscle. Rostral white muscle in cod is kinetically faster than caudal muscle (Davies et al., 1995). The $t_{\mathrm{W} 50}$ values for cod average $54.0 \pm 2.9 \mathrm{~ms}$ (mean \pm S.E.M.) for rostral single fibers and $88.3 \pm 8.0 \mathrm{~ms}$ for caudal fibers. Further, molecular correlates to variations in cod have been found (Thys et al., 1998): as with bass, cod rostral white muscle has higher levels of TnT-2, parvalbumin and other $\mathrm{Ca}^{2+}$-binding proteins. For these two species, there is apparently a common mechanism being employed for regulation of contractile properties. In contrast, longitudinal axial muscle relaxation rates are similar for the short-horned sculpin Myoxocephalus scorpius: $t_{\mathrm{W} 50}$ averages $136 \pm 41 \mathrm{~ms}$ (mean \pm S.D.) for rostral single fibers while caudal single fibers average $134 \pm 51 \mathrm{~ms}$ (Johnston et al., 1993). Comparing muscle protein expression patterns of sculpin relative to cod and largemouth bass would allow greater insight into the commonalities and divergences of regional muscle protein expression across fishes.

\section{Consequence of longitudinal variation in kinetics}

A longitudinal variation in contractile properties such as activation and relaxation rate could have profound effects on undulatory locomotion. For most vertebrates that move via axial undulation, the wave of excitation (electrical activation measured by EMGs) propagates faster down the body than the actual wave of bending for both slow (red) and fast (white) muscle (Altringham and Ellerby, 1999), for example, eel Anguilla rostrata (Gillis, 1998), bluegill Lepomis macrochirus (Jayne and Lauder 1993), largemouth bass 
Micropterus salmoides (Jayne and Lauder, 1995b), rainbow trout Oncorhynchus mykiss (Hammond et al., 1998; Coughlin, 2000) and snakes Crotalus cerastes, Nerodia fasciata and Elaphe obsolete (Jayne, 1988). This leads to rostral-caudal variations in the activation conditions encountered by muscle. The onset of activation of rostral muscle is just before peak muscle length, whereas caudal muscle typically shows a greater phase shift with the onset of muscle activity coming well before peak muscle length. Also, rostral muscle is typically activated for a longer proportion (duty cycle) of each tailbeat cycle compared to caudal muscle (Altringham and Ellerby, 1999).

Longitudinal variations in contraction kinetics and protein composition of the white muscle, as reported here, could affect patterns of power production (i.e. muscle function) during fast swimming in fishes. Differences in the phase relation between strain and excitation can have profound effects on the mechanical behaviour of skeletal muscle (Josephson, 1985; Altringham et al., 1993; Rome et al., 1993; Coughlin, 2000). The relationship of the timing of muscle activity to its length change cycle is considered critical to power production by muscle (Altringham and Ellerby, 1999). Anterior muscle exhibits a small phase shift and fast activation and relaxation kinetics. Consequently it is predicted to generate high force levels just as the muscle reaches peak length during the shortening phase. Posterior muscle, which commonly exhibits a greater phase shift and shorter duty cycles, appears to generate force during lengthening. Since variations in contractile properties also affect power output, the remaining question is how do differences in contractile proteins and their properties contribute to force and power production at each position in a swimming fish?

To determine how patterns of muscle activity and contractile properties interact, workloop experiments could be used to provide empirical measurements of work and power output (Josephson, 1985). Such studies would be able to test predictions concerning the relationship of rostral-caudal variation in protein composition and contraction kinetics to longitudinal patterns of power production in white muscle. Workloop experiments, however, require detailed in vivo data on muscle strain and activation conditions, so technically challenging measurements of white muscle strain and EMG activity are needed. In one workloop study on white muscle function in fishes, anterior white muscle of saithe was shown to generate substantially more power than posterior muscle during swimming (Altringham et al., 1993). As research on red muscle continues to show a diversity of solutions to the problem of powering steady swimming (Altringham and Ellerby, 1999; Coughlin, 2000), more work is needed to examine how white muscle function during fast swimming may vary across fish species.

We thank Besty Kempter, Bryan Kempter and Clint King for supplying the experimental animals, Steve Wainwright for advice and Stephen Katz for comments on an earlier draft of this manuscript. This work was supported by an NIH Grant
(EY-11377) to F.H.S. and an NSF-RUI Grant (IBN-9604140) to D.J.C.

\section{References}

Altringham, J. D. and Johnston, I. A. (1990). Modelling muscle power output in a swimming fish. J. Exp. Biol. 148, 395-402.

Altringham, J. D., Wardle, C. S. and Smith, C. I. (1993). Myotomal muscle function at different locations in the body of a swimming fish. J. Exp. Biol. 182, 191-206.

Altringham, J. D. and Ellerby, D. J. (1999). Fish swimming: patterns in muscle function. J. Exp. Biol. 202, 3397-3403.

Briggs, M. M., Jacoby, J., Davidowitz, J. and Schachat, F. H. (1988). Expression of a novel combination of fast and slow troponin $\mathrm{T}$ isoforms in rabbit extraocular muscles. J. Mus. Res. Cell Motil. 9, 241-247.

Coughlin, D. J., Burdick, J., Stauffer, K. A. and Weaver, F. E. (2001). Rainbow trout display a developmental shift in red muscle kinetics, swimming kinematics and myosin heavy chain isoform. J. Fish Biol. 58, 701-715.

Coughlin, D. J. (2000). Power production during steady swimming in largemouth bass and rainbow trout. J. Exp. Biol. 203, 617-629.

Davies, M. L. F., Johnston, I. A. and Van de Wal, J. (1995). Muscle fibers in rostral and caudal myotomes of the Atlantic cod (Gadus morhua L.) have difference mechanical properties. Physiol. Zool. 68, 673-697.

Eisenberg, E. and Kielley, W. W. (1974). Troponin-tropomyosin complex. Column chromatographic separation and activity of the three, active troponin components with and without tropomyosin present. J. Biol. Chem. 249, 4742-4748.

Gillis, G. B. (1998). Neuromuscular control of anguilliform locomotion: Patterns of red and white muscle activity during swimming in the American eel, Anguilla rostrata. J. Exp. Biol. 201, 3245-3256.

Hammond, L., Altringham, J. D. and Wardle, C. S. (1998). Myotomal slow muscle function of rainbow trout Oncorhynchus mykiss during steady swimming. J. Exp. Biol. 201, 1659-1671.

Hoffer, J. A., Loeb, G. E., Sugano, N., Marks, W. B., O'Donovan, M. J. and Pratt, C. A. (1987). Cat hind limb motorneurons during locomotion: III. Functional segregation in sartorius. J. Neurophysiol. 57, 554-562.

Jayne, B. C. (1988). Muscular mechanisms of snake locomotion: an electromyographic study of the sidewinding and concertina modes of Crotalus cerastes, Nerodia fasciata and Elaphe obsoleta. J. Exp. Biol. 140, $1-33$.

Jayne, B. C. and Lauder, G. V. (1993). Red and white muscle activity and kinematics of the escape response of the bluegill sunfish during swimming. J. Comp. Physiol. A 173, 495-508.

Jayne, B. C. and Lauder, G. V. (1994). Comparative morphology of the myomeres and axial skeleton in four genera of centrarchid fishes. J. Morph. 197, 159-181.

Jayne, B. C. and Lauder, G. V. (1995a). Are muscle fibers within fish myotomes activated synchronously? Patterns of recruitment within deep myomeric musculature during swimming in largemouth bass. J. Exp. Biol. 198, 805-815.

Jayne, B. C. and Lauder, G. V. (1995b). Red muscle motor patterns during steady swimming in largemouth bass: effects of speed and correlation with axial kinematics. J. Exp. Biol. 198, 657-670.

Johnston, I. A. Franklin, C. E. and Johnson, T. P. (1993). Recruitment patterns and contractile properties of fast muscle fibres isolated from rostral and caudal myotomes of the short-horned sculpin. J. Exp. Biol. 185, 251-265.

Josephson, R. K. (1985). Mechanical power output from striated muscle during cyclic contractions. J. Exp. Biol. 114, 493-512.

Laemmli, U. K. (1970). Cleavage of structural proteins during the assembly of the head of bacteriophage T4. Nature 227, 680-685.

Long, J. A. (1995). The Rise of Fishes: 500 Million Years of Evolution. The John Hopkins University Press, Baltimore. 223pp.

McGlinchey, S., Forry, J. A., Saporetti, K. A., Pohronezny, J. and Coughlin, D. J. (2001). Red muscle function during steady swimming in brook trout, Salvelinus fontinalis. Comp. Biochem. Physiol. 129A, 727-738.

Müntener, M. L., Kaser, J. and Berchtold, M. W. (1995). Increase of skeletal muscle relaxation speed by direct injection of parvalbumin cDNA. Proc. Natl. Acad. Sci. USA 92, 6504-6508.

Pepinski, R. B. (1983). Localization of lipid-protein and protein-protein interactions within the murine retrovirus gag precursor by a novel peptidemapping technique. J. Biol. Chem. 258, 11229-11235. 
Rushbrooke, J. I., Weiss, C., Yao, T. T. and Jianmin, L. (1988). Complexity of myosin species in the avian posterior latissimus dorsi muscle. J. Mus. Res. Cell Motil. 9, 552-562.

Rome, L. C., Swank, D. and Corda, D. (1993). How fish power swimming. Science 261, 340-343.

Schachat, F. H., Bronson, D. D. and McDonald, O. B. (1980). Two kinds of slow skeletal muscle fibers which differ in their myosin light chain complements. FEBS Lett. 122, 80-82.

Schachat, F. H., Diamond, M. S. and Brandt, P. W. (1987). Effect of different troponin T-tropomyosin combinations on thin filament activation. J. Mol. Biol. 198, 551-554.

Schiaffino S. and Reggiani, C. (1996). Molecular diversity of myofibrillar proteins: gene regulation and functional significance. Physiol. Rev. 76, 371-423.
Shigeoka, C. A. (1997). Regional muscle shortening and lengthening within the pigeon pectoralis during various modes of flight. Am. Zool. 37, 55A.

Thys, T. (1997). Spatial variation in epaxial muscle activity during prey strike in largemouth bass Micropterus salmoides. J. Exp. Biol. 200, 3012-3031.

Thys, T. M., Blank, J. M. and Schachat, F. H. (1998). Rostral-caudal variation in troponin $\mathrm{T}$ and parvalbumin correlates with differences in relaxation rates of cod axial muscle. J. Exp. Biol. 201, 2993-3001.

Towbin, H., Straehlin, T. and Gordon, J. (1979). Electrophoretic transfer of proteins from polyacrylamide gels to nitrocellulose sheets: procedure and some applications. Proc. Natl. Acad. Sci. USA 76, 4350-4354.

Wardle, C. S., Videler, J. J. and Altringham, J. D. (1995). Tuning in to fish swimming waves: body form, swimming mode and muscle function. J. Exp. Biol. 198, 1629-1636. 